\title{
Spatiotemporal Variability and Change of the South China Spring Precipitation during 1961-2012
}

\author{
Hong-Lan Liu,, Qiang Zhang, ${ }^{2}$ Jun-Qin Guo, ${ }^{3}$ Jun-Guo Zhang, ${ }^{4}$ and Sheng Wang ${ }^{5}$ \\ ${ }^{1}$ Zhangye Meteorological Bureau, Zhangye 734000, China \\ ${ }^{2}$ Key Laboratory of Arid Climatic Change and Disaster Reduction of Gansu Province, Key Laboratory of Arid Climate Change and \\ Disaster Reduction of China Meteorological Administration, Institute of Arid Meteorology, China Meteorological Administration, \\ Lanzhou 730020, China \\ ${ }^{3}$ Northwest Regional Climate Center, Lanzhou 730020, China \\ ${ }^{4}$ Zhangye Middle School, Zhangye 734000, China \\ ${ }^{5}$ Jinta County Meteorological Bureau, Jinta 735300, China
}

Correspondence should be addressed to Hong-Lan Liu; gszylhl@126.com

Received 6 December 2014; Revised 4 March 2015; Accepted 27 April 2015

Academic Editor: June-Yi Lee

Copyright (c) 2015 Hong-Lan Liu et al. This is an open access article distributed under the Creative Commons Attribution License, which permits unrestricted use, distribution, and reproduction in any medium, provided the original work is properly cited.

\begin{abstract}
We analyze precipitation data from 47 meteorological stations spanning between 1961 and 2012 and NCEP/NCAR reanalysis to understand spatiotemporal variability and change of spring precipitation of South China and their relations to atmospheric circulations. Empirical orthogonal function (EOF) analysis and rotated EOF (REOF) are used to reveal dominant spatial structures of precipitation anomaly and Mann-Kendall testing method to determine the temporal locations of abrupt changes during the analyzed time span. We find that the first spatial mode of the spring precipitation of the South China has a domain uniform structure; the second is dominated by a spatial dipole; and the third contains six variability centers. 1980s was the decade of the largest amount of precipitation while 1960s the decade of the smallest amount of precipitation. The spring precipitation also appeared to have a decreasing trend since 2000. We also find that spring precipitation of the South China has experienced a few abrupt changes: sudden increment at 1964, sudden decrement at 2002, and sudden increment at 1995. In addition to these abrupt changes, the precipitation could also be characterized by variability of multiple temporal scales, with dominant periodicities of 4 years, 8 years, and 14 years. The South China spring precipitation is also closely tied to the atmospheric circulations: when Aleutian Low strengthens, westerly weakens, and the center of the Western Pacific subtropical high shifts southeastward in the early spring; and the South China precipitation tends to be abundant (positive anomaly). In contrast, when Ural ridge strengthens, the southern branch of the East Asian trough weakens and the Western Pacific subtropical high shifts northwestward in the early spring, the South China precipitation tends to be reduced (negative anomaly).
\end{abstract}

\section{Introduction}

China is one of the most vulnerable countries in the world to natural disasters, with annual loss caused by weather/climate disasters mounts up to $3 \%-6 \%$ of the gross domestic product. The frequent occurrences of draught have been threatening food product and social security and thereby creating tremendous challenge to socioeconomic conditions and environment-ecology $[1,2]$. The South China $\left(104^{\circ} 26^{\prime}-\right.$ $117^{\circ} 20^{\prime} \mathrm{E}, 20^{\circ} 09^{\prime}-26^{\circ} 24^{\prime} \mathrm{N}$ ) locates in the southeastern edge of the Eurasian continent and has 41 million square kilometers, including Guangdong Province and Guangxi Zhuang
Autonomous Region, spreading over both tropical and subtropical regions surrounded by the South China Sea to the south and the Pacific Ocean to the east. The region is topographically complicated and features diverse stereoscopic climate regimes, especially in the vertical direction. While the region processes abundant climatic resources, it also experiences frequently occurred meteorological disasters [3].

The climate of South China is not only significantly affected by the low latitudes atmospheric circulation but also influenced by the middle to high latitudes atmospheric circulations. Low and high latitude circulation systems interact with each other and lead to diverse weather/climate patterns 
in South China. In addition to that, numerous studies have also shown that climate variability and change in China, especially South China, are closely related to the coupled air-sea interactions in low latitudes. In general, the lowlevel basic flow in South China features three different types: the subtropical westerly, the equatorial westerly, and tropical easterly. Although these three types of basic flow appear in all four seasons, their locations, intensities, and ranges can vary significantly from season to season. Also, these winds are most baroclinic, with alternating easterly and westerly in the vertical. In winter, westerly dominates in upper troposphere and low-level features northeast monsoon. In summer, southwest monsoon prevails in the middle-low troposphere and steady easterly in upper troposphere.

Since 1980s, the region has recorded numerous disastrous extreme climatic events which are believed to tie with the global climate change $[4,5]$. It appeared that the South China spring drought occurred with increasing frequency most recently and some of drought events even lasted for a few seasons, for example, the 2003 drought event that influenced most regions of China south to the Yangtze River and continued through the summer and autumn, the 2005 drought in South China that lasted from autumn to spring, and 2010 severe spring drought in South China [6-9], which caused drastic consequences in agricultural, industrial, and civil water usage. Wen et al. [10] performed a quantitative diagnosis for the mechanisms of spring droughts in South China. Gu et al. [11] analyzed the variation and precursor of Guangzhou spring rainfall. Zhou et al. [12] provided AprilMay persistent drought events in South China and the related general circulation background. Li et al. [13] demonstrated the zonal seesaw-like distribution of spring precipitation over South China and characteristics of atmospheric circulation in anomalous climate years. Li et al. [14] found the characteristics of the atmospheric water vapor and its relationship with rainfall in South China in northern autumn, winter, and spring. Wan et al. [15] discussed temporal variations of the spring persistent rains and SCS subtropical high and their correlations to the circulation and precipitation of the East Asia summer monsoon. Han et al. [16] revealed the interannual variation of spring precipitation and circulation in South China as simulated by a coupled model. Since the spring is the most important season for crop growing, the study of the characteristics of South China spring precipitation and their physical causes bears significant meanings.

Previous studies using statistical analysis have showed that the South China spring droughts were often of large scales, in contrast to the relatively spatiotemporally fragmented character of summer-autumn droughts. In this study, we aim to provide more detailed spatiotemporal characteristics of spring precipitation in South China.

\section{Data and Methods}

The South China in this study refers to the territory of China enclosed by a rectangle from $104^{\circ} 26^{\prime}$ to $117^{\circ} 20^{\prime} \mathrm{E}$ and from $20^{\circ} 09^{\prime}$ to $26^{\circ} 24^{\prime} \mathrm{N}$, as shown in Figure 1. This part of China includes Guangdong Province and Guangxi

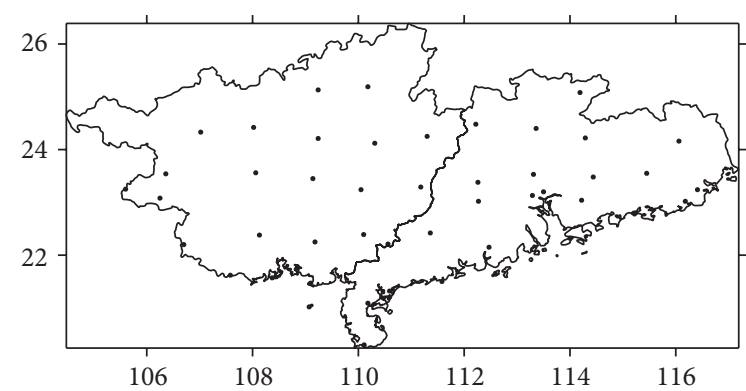

FIgURE 1: Locations of meteorological stations (dots) providing precipitation data.

Zhuang Autonomous Region. The data analyzed include (1) spring (March to May) precipitation (see Figure 2) and (2) NCEP/NCAR reanalysis with a resolution of $2.5^{\circ} * 2.5^{\circ}$.

Precipitation data used in this paper is monthly precipitation data of 730 stations from 1961 to 2012, provided by the National Climate Center (China). The daily NCEP/NCAR reanalysis data during the same period includes wind, water vapor flux, geopotential height field, and vertical velocity field.

We selected all of the stations located in the east of $104^{\circ} \mathrm{E}$ and the south of $27^{\circ} \mathrm{N}$ on behalf of South China. There are 47 stations evenly distributed in the region, which could well represent South China (Figure 1).

The empirical orthogonal function (EOF) analysis and rotated EOF (REOF) $[17,18]$ are used to determine the basic characteristics of South China spring precipitation as well as their spatiotemporal structures of variability and change. Mann-Kendall testing method $[17,18]$ is used to determine the temporal locations of abrupt changes of spring precipitation, at an a priori set $a=0.05$ significance level. The trend is a fifth order running trend and its statistical significance is also tested using nonparametric Mann-Kendall method. The periodicity information of the spring precipitation is obtained using spectrum analysis. $t$-testing $[17,18]$ is also used to test statistical significance of abrupt changes.

\section{Characteristics of South China Precipitation}

3.1. Basic Climate Characteristics. The South China features a wide spread of spring precipitation from $212.1 \mathrm{~mm}$ to $808.3 \mathrm{~mm}$, with a mean value $487.8 \mathrm{~mm}$. Spring precipitation consists of $15.3 \%$ to $40.2 \%$ of its annual total for different regions, with a mean value $28.9 \%$. Figure 2 plots the mean and the standard deviation of precipitations over the whole South China region. As revealed by Figure 2 the eastern part of South China has abundant rainfall in spring while the western part has much less rainfalls. The center of the fewest spring precipitation locates at Weizhou Island $\left(109^{\circ} 06^{\prime} \mathrm{E}, 21^{\circ} 02^{\prime} \mathrm{N}\right)$ of Guangxi Zhuang Autonomous Region, with spring precipitation of only $212.1 \mathrm{~mm}$. The largest spring precipitation occurs in Fuogang $\left(113^{\circ} 31^{\prime} \mathrm{E}, 23^{\circ} 53^{\prime} \mathrm{N}\right)$ of Guangdong Province, with a value over $800 \mathrm{~mm}$. The large ratio (about 4) between the values of maximum and of minimum precipitation indicates the unevenness of the precipitation distribution over South 


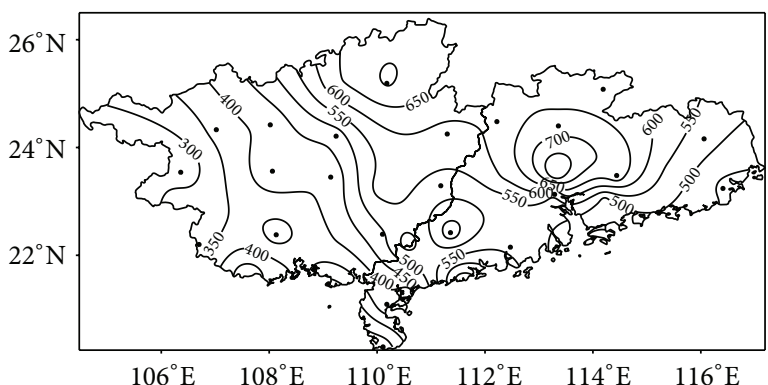

(a)

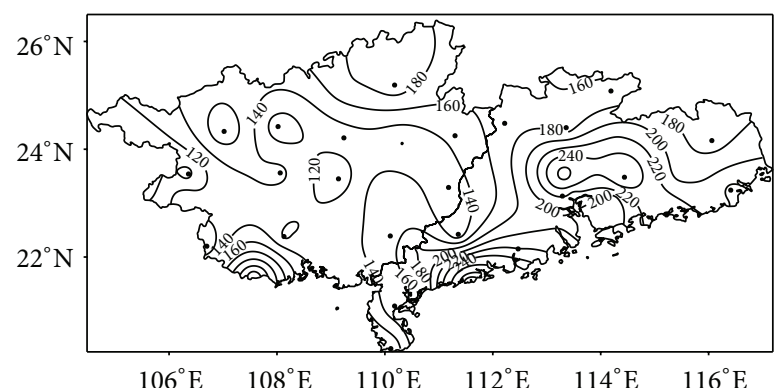

(b)

FIGURE 2: Long-term mean spring precipitation (a) and its standard deviation (b) in South China.

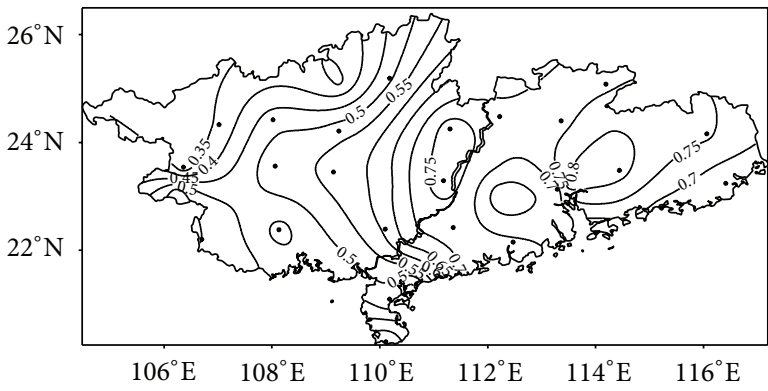

(a)

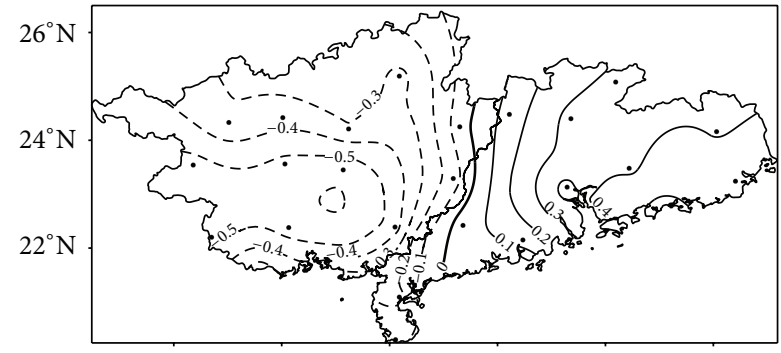

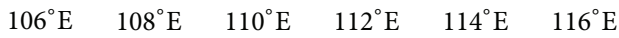

(b)

FIGURE 3: The first (a) and the second (b) eigenvectors of spring precipitation in South China.

China. The standard deviation of the precipitation has similar spatial structure of the precipitation itself, with its maximum $(349.3 \mathrm{~mm})$ locating at Yangjiang $\left(111^{\circ} 58^{\prime} \mathrm{E}, 21^{\circ} 50^{\prime} \mathrm{N}\right)$ of southern Guangdong Province and a minimum $(92.3 \mathrm{~mm})$ striped along Napo $\left(105^{\circ} 50^{\prime} \mathrm{E}, 23^{\circ} 25^{\prime} \mathrm{N}\right)$ and Baise $\left(106^{\circ} 36^{\prime} \mathrm{E}\right.$, $23^{\circ} 54^{\prime} \mathrm{N}$ ) region of western Guangxi Zhuang Autonomous Region. In general, the eastern and southeastern regions of the South China have abundant rainfall; and the remaining parts of South China have much less rainfall. This pattern of the spring precipitation indicates that the spring precipitation in the South China may be significantly influenced by the monsoon southeasterly from the Pacific Ocean.

3.2. Spatial Structure of Precipitation Anomaly. Table 1 presents the variance contribution from the first eight eigenvectors (empirical orthogonal functions). The convergence of the sum of eigenvectors for South China precipitation is relatively slow: the accumulated variance contribution from the first two eigenvectors is $52.1 \%$, the first four $63.1 \%$, and the first eight $76.6 \%$. The first two eigenvectors are displayed in Figure 3. The first eigenvector (EOF) has positive values all over the domain, with the maximum value at Zengcheng $\left(113^{\circ} 50^{\prime} \mathrm{E}, 23^{\circ} 20^{\prime} \mathrm{N}\right)$ of central Guangdong Province. The result implies that the South China may be considered as one natural climatological regime for the spring precipitation over the South China, with its representative station being Zengcheng $\left(113^{\circ} 50^{\prime} \mathrm{E}\right.$, $23^{\circ} 20^{\prime} \mathrm{N}$ ) of Guangdong Province which has a value 0.82 . The second eigenvector is dominated by a dipole, with a north-southward zero line passing the neighborhoods of Hezhou $\left(111^{\circ} 30^{\prime} \mathrm{E}, 24^{\circ} 25^{\prime} \mathrm{N}\right)$ of Guangxi and Luoding $\left(111^{\circ} 36^{\prime} \mathrm{E}, 22^{\circ} 42^{\prime} \mathrm{N}\right)$ of Guangdong, coincided with the border between Guangxi and Guangdong. To the east of the zero line, the representative station is Wuhua $\left(115^{\circ} 45^{\prime} \mathrm{E}, 23^{\circ} 55^{\prime} \mathrm{N}\right)$ of Guangdong Province, with a value of 0.46 ; and to the west, the representative station is Laibin $\left(109^{\circ} 14^{\prime} \mathrm{E}, 23^{\circ} 45^{\prime} \mathrm{N}\right)$ of Guangxi Zhuang Autonomous Region, with a value of -0.58 , implying that the precipitation of South China spring precipitation has a component of contrasting changes in the east and west parts of the South China.

To maximize the variance explained by different spatial structures, we rotate the first eight eigenvectors obtained using EOF. The first five rotated EOFs explain $67.2 \%$ of variance. The sum of these five rotated EOFs illustrates six distinctive natural climatological regimes: (1) the northern part of the South China which features hilly areas of both Guangdong and Guangxi; (2) the northwestern region of Guangxi; (3) the southwestern region of Guangxi; (4) the central South China (including the central parts of both Guangdong and Guangxi); (5) the southern South China region (including the central regions of both Guangdong and Guangxi); and (6) Leizhou Peninsula region.

\subsection{Interannual and Decadal Variability of the South China} Spring Precipitation. Based on the first time coefficient sequence of EOF and precipitation anomaly percentage of each station, the variation law of was analyzed. By the first time coefficient curve shown in the newly added Figure 4, 
TABLE 1: Different EOF variance contributions of spring precipitation in South China.

\begin{tabular}{lcccccccc}
\hline Number & 1 & 2 & 3 & 4 & 5 & 6 & 7 & 8 \\
\hline Variance contribution (\%) & 39.0 & 13.1 & 5.7 & 5.3 & 4.1 & 3.7 & 2.9 & 2.8 \\
\hline Accumulated variance contribution (\%) & 39.0 & 52.1 & 57.8 & 63.1 & 67.2 & 70.9 & 73.8 & 76.6 \\
\hline
\end{tabular}

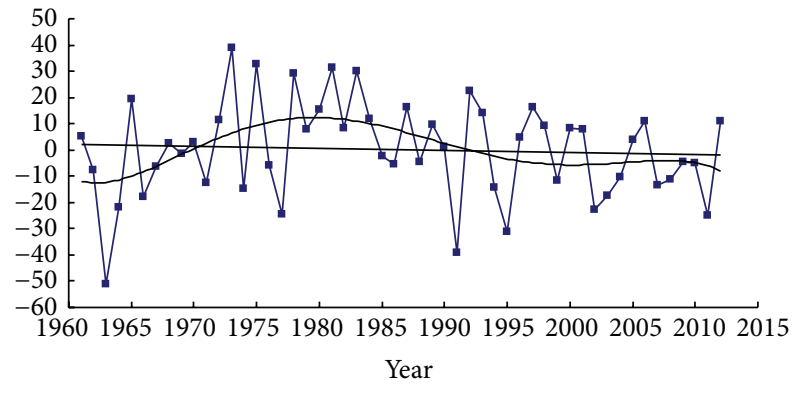

FIGURE 4: Yearly variation of the first time series of precipitation of South China spring precipitation.

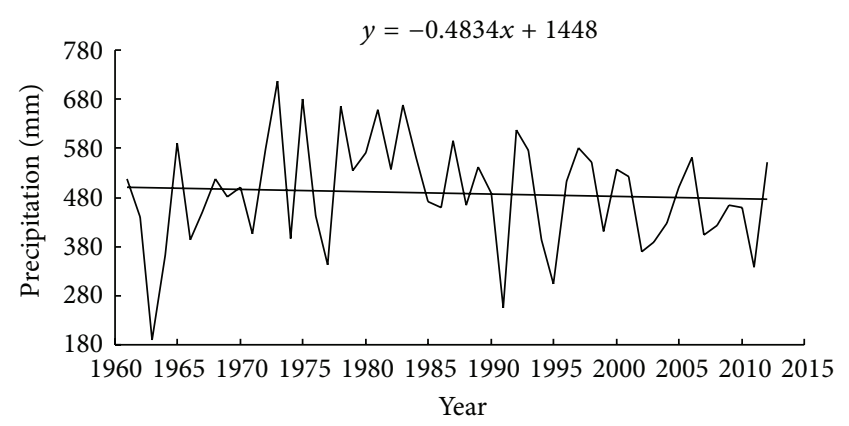

FIGURE 5: The overall variability and changes of spring precipitation in South China.

it could be found that spring precipitation in South China decreased slowly in overall tendency since the 1960s. There are two relatively wetter periods in the 1970s and the 1980 s. The precipitation shows a decreasing trend since the late 1980s.

To quantify the variability of South China spring precipitation, we calculate the percentages of positive anomaly and negative anomaly. Over the temporal span of data, 27 years had positive anomaly and 25 years negative anomaly. The interannual variability of spring precipitation is evident, for example, the fluctuation in 1973 reached a maximum value of $716.5 \mathrm{~mm}$ while the fluctuation in 1963 is as small as $189.9 \mathrm{~mm}$. The maximum interannual fluctuation is almost four times as large as that of the minimum. From Figure 5, it can be identified that the fluctuating spring precipitation in South China has been slowly decreasing in the last 52 years. Further analysis of the increased percentages of positive or negative anomalies over different decades (with respect to 1981-2010 mean) is presented in Figure 6. In 1960s, the increased percentage of anomaly is positive in northwestern Guangxi and negative elsewhere. The increased positive percentage of spring rainfall anomaly was most evident in Fengshan $\left(107^{\circ} 02^{\prime} \mathrm{E}, 24^{\circ} 33^{\prime} \mathrm{N}\right)$ region of Guangxi, reaching a value of $21 \%$. In contrast, Shantou $\left(116^{\circ} 41^{\prime} \mathrm{E}, 23^{\circ} 24^{\prime} \mathrm{N}\right)$ of eastern Guangdong has a decreased positive (increased negative) anomaly percentage of $-35 \%$. In 1970s, except the southeastern coastal region of Guangdong, the whole South China was dominated by positive anomalies. The positive anomaly percentage was most evident in southern coastal Guangxi, with an increased positive anomaly percentage of $50 \%$. In contrast, the southern coastal Guangdong had a negative anomaly percentage of $-24 \%$. In 1980 s, the South China was dominated by positive anomaly percentage except the northwestern region of Guangxi. The largest positive anomaly percentage (31\%) appeared in the southeastern coastal area of Guangdong while the largest negative anomaly percentage $(-5 \%)$ appeared in Liuzhou $\left(109^{\circ} 24^{\prime} \mathrm{E}, 24^{\circ} 21^{\prime} \mathrm{N}\right)$ of Guangxi. In 1990s, the northern part of the South China and Leizhou Peninsula had positive anomaly percentage while the other regions of the South China had negative anomaly percentages. The largest positive percentage anomaly, with a value of $14 \%$, appeared in Zhanjiang $\left(110^{\circ} 18^{\prime} \mathrm{E}, 21^{\circ} 09^{\prime} \mathrm{N}\right)$ of Leizhou Peninsula while the largest negative anomaly percentage appeared in Huilai $\left(116^{\circ} 18^{\prime} \mathrm{E}, 23^{\circ} 02^{\prime} \mathrm{N}\right)$ of coastal southeastern Guangdong and Baise $\left(106^{\circ} 36^{\prime} \mathrm{E}, 23^{\circ} 54^{\prime} \mathrm{N}\right)$ of western Guangxi. In 2000s, the positive anomaly percentage was small and only appeared at Guangzhou $\left(113^{\circ} 29^{\prime} \mathrm{E}\right.$, $\left.23^{\circ} 13^{\prime} \mathrm{N}\right)$, Dianbai $\left(110^{\circ} 59^{\prime} \mathrm{E}, 21^{\circ} 32^{\prime} \mathrm{N}\right)$ of Guangdong, and Baise $\left(106^{\circ} 36^{\prime} \mathrm{E}, 23^{\circ} 54^{\prime} \mathrm{N}\right)$ of Guangxi, with its largest value only reaching $8 \%$ at Baise $\left(106^{\circ} 36^{\prime} \mathrm{E}, 23^{\circ} 54^{\prime} \mathrm{N}\right)$. Elsewhere, negative anomaly percentage dominated, with the largest value $(-19 \%)$ appeared in eastern Guangdong.

In summary, 1980s was the decade of largest amount of spring precipitation in the last half century in the South China. 1960s was dominated by above normal spring precipitation in northwestern part of South China and below normal spring precipitation elsewhere. 1970s featured above normal spring precipitation over most of the South China. 1990s had above normal spring precipitation in northern part of South China and below normal in the southern part. In 2000s, spring precipitation was generally below average.

\subsection{Multiscale Analysis of the South China Spring Precipi-} tation. The linear fitting to spring precipitation anomaly in the South China shows a slow steady decrease of spring precipitation, with a slope of -0.48 . From Figure 5 , it is identified that the spring precipitation of South China was above normal during 1968-1992 and was below normal during 1961-1967 and 1993-2000. The below normal spring precipitation in the first decade of 21st century indicates that the amount of South China spring precipitation had reduced during the first decade of the 21st century.

To better quantify the multiscale nature of the South China spring precipitation, wavelet analysis $[17,18]$ of spring 


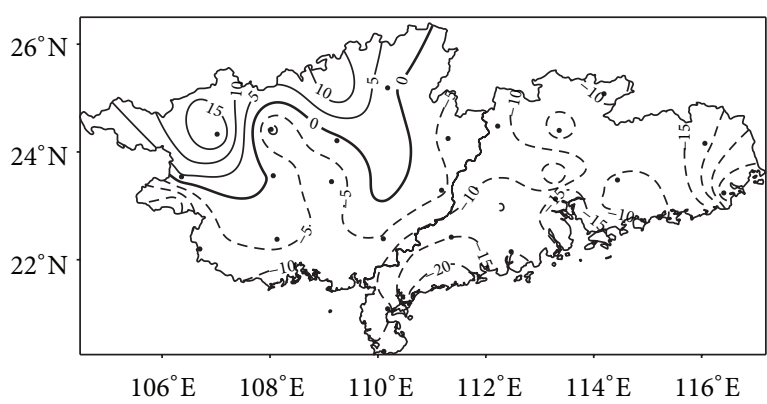

(a)

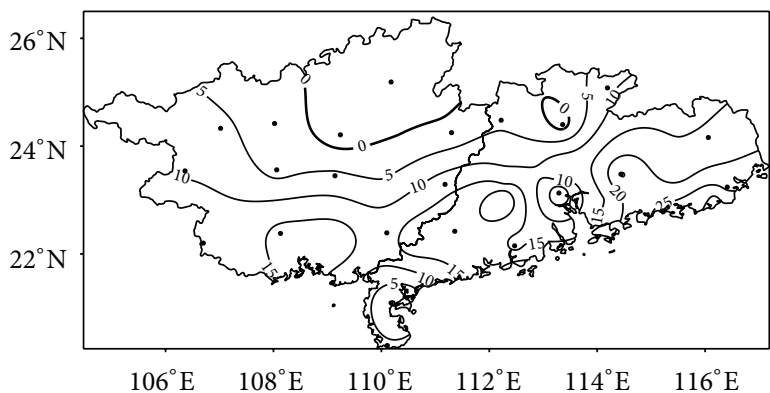

(c)

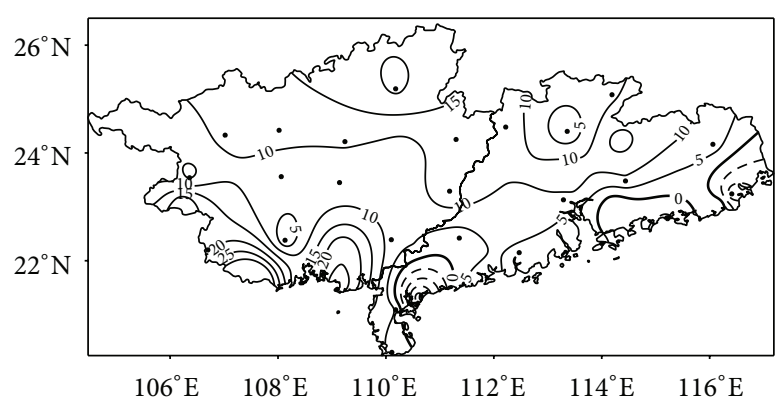

(b)

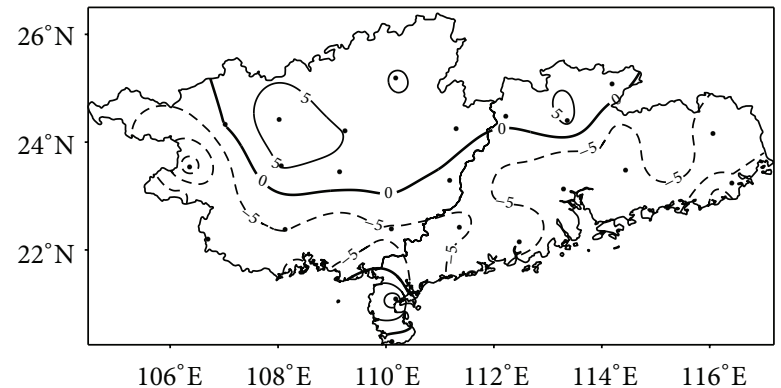

(d)

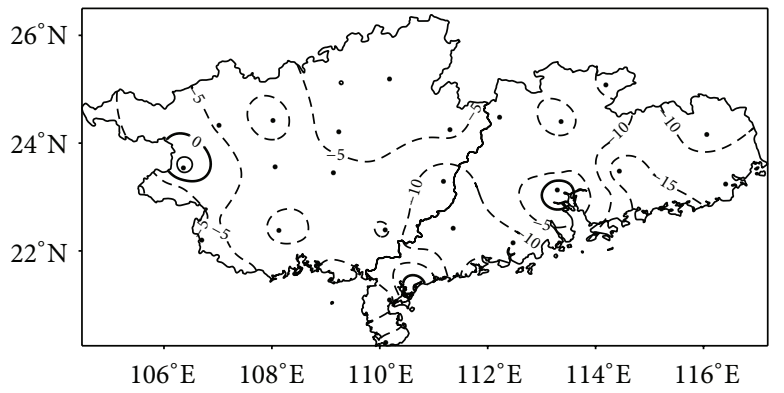

(e)

FIGURE 6: The spring precipitation anomaly percentage in the South China ((a) 1960s, (b) 1970s, (c) 1980s, (d) 1990s, and (e) 2000s).

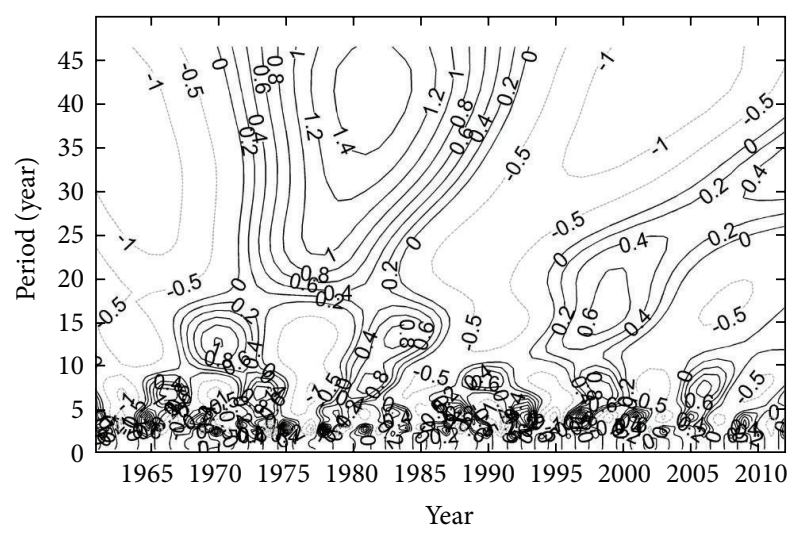

FIGURE 7: Wavelet analysis of spring precipitation in South China.

precipitation of South China is carried out, with the corresponding results presented in Figure 7. The dominant timescales of variability of the South China spring precipitation are 7 years, 12 to 14 years, and 40 years. The 12- to 14-year variability occurred between 1961 and 2012; and the variability of South China spring precipitation had a belowabove-below-above-below-above-below pattern, with 19611967, 1975-1980, 1987-1994, and 2004-2010 below normal and 1968-1974, 1981-1986, and 1995-2003 above normal. The latest below normal pattern appeared to have already well passed its peak and it is likely that the above normal precipitation will occur in the next decade. On the timescale of about 40 years, the South China spring precipitation has experienced below-above-below normal pattern, with below normal precipitation occurring during 1961-1972 and after 1992 and above normal during 1973-1992. The latest belownormal period appears to be close to or to have reached its zero-crossing phase, implying that the variability South China spring precipitation on that timescale may enter above normal phase in the coming years. The variability of the time scale of around 7 years has large amplitude modulation and has much complicated patterns. Prediction using the 


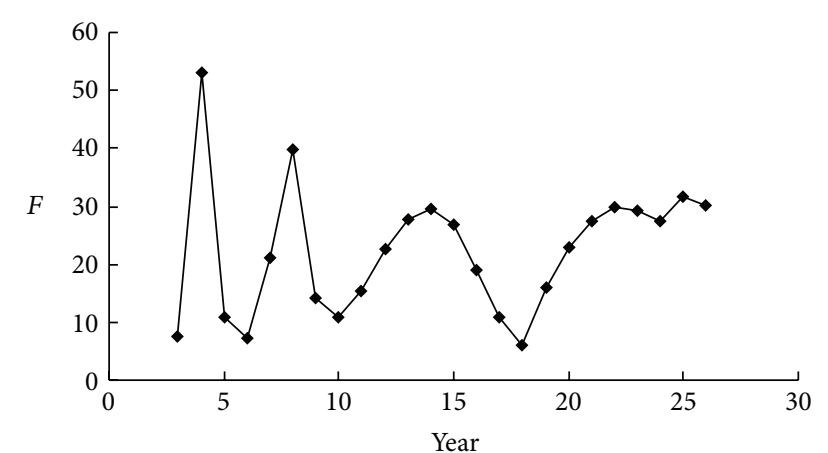

FIgURE 8: Spectral analysis of the South China spring precipitation.

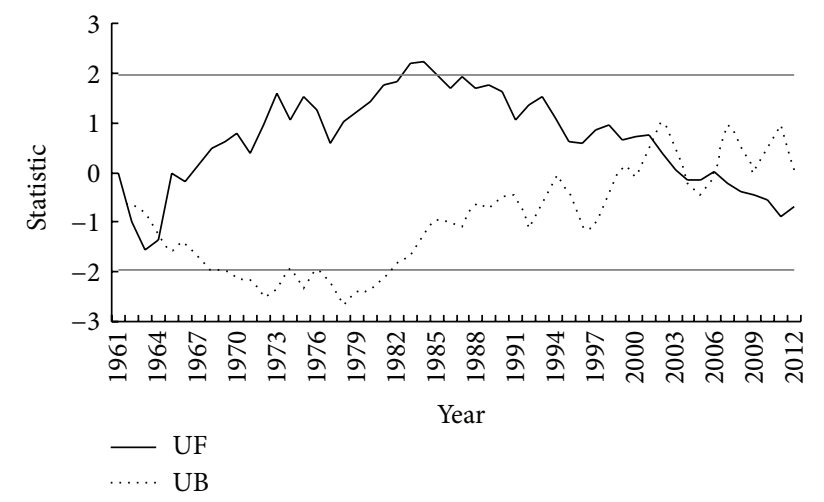

FIGURE 9: Mann-Kendall testing of abrupt changes of the South China spring precipitation (The $a=0.05$ significance level is given by the straight line).

periodicity but not the amplitude modulation may lead to larger error.

Spectral analysis of the spatial mean of spring precipitation of South China shows peaks of 4 years, 8 years, and 14 years in spectral diagram, which is presented in Figure 8. This kind of periodicity passes the significance test at level 0.05 .

\section{Abrupt Changes of Spring Precipitation in South China}

To determine whether the spring precipitation of South China has experienced abrupt changes, we use Mann-Kendall $[17,18]$ testing method to analyze area averaged precipitation series. Mann-Kendall testing method is a nonparametric method and widely used. The method does not assume any a priori distribution of sample and is not sensitive to small number of abnormal extremes. The method can be applied to both categorized data and series albeit it only involves intuitively simple calculation. One of the advantages of Mann-Kendall testing method is its capability of determining the locations of mean or slope changes; and therefore, it is a method that can detect abrupt changes. Figure 9 presents the detecting results. It is evident that the spring precipitation increment started at mid-1960s and maintained until mid-1980s. From mid-1980s, the spring precipitation began to decrease. An abrupt increment occurred in 1964 and an abrupt decrement occurred in 2002. These two abrupt changes are statistically significant at a significance level of $a=0.05\left(u_{0.05}= \pm 1.96\right)[17,18]$.

\section{The South China Spring Precipitation and the Abnormal Atmospheric Circulations}

The South China spring climate is significantly influenced by subtropical and mid and high latitude atmospheric circulations. From the composites of $850 \mathrm{hPa}$ level wind fields and geopotential height fields for abundant South China spring precipitation years and for scarce South China spring precipitation years (figures omitted), one can identify that the abundant (scarce) spring precipitation of the South China coincides with abnormally strong (weak) and wide (narrow) subtropical high, stronger (weaker) Eastern Asia low, and larger (smaller) geopotential gradient between these two systems. Such a coincidence is also reflected in the composite of geopotential gradient at $500 \mathrm{hPa}$ (Figure 10(a)). The larger positive geopotential gradient center, with its maximum value exceeding 9 dagpm, appears in the $10^{\circ}-20^{\circ} \mathrm{N}$ zone of the western Pacific, implying the strengthening of the subtropical high. At the same time, a negative center to the east of the Tibetan Plateau appears, indicating a stronger low. From the basic dynamics, it can be inferred that such type of anomalous pressure gradient can lead to the strengthening of the southwesterly $[19,20]$ at low levels. It is clear that the years of abundant (scarce) spring precipitation in the South China correspond to the strengthened (weakened) low-level southwesterly, which is also evident from the composite of the difference of the wind field at $850 \mathrm{hPa}$ level between the abundant spring precipitation and scarce spring precipitation years (Figure 10(b)). Figure 10(b) also displays that anomalous anticyclonic circulation appears in the western Pacific subtropical high region, centered in the vicinity of $\left(138^{\circ} \mathrm{E}\right.$, $17^{\circ} \mathrm{N}$ ), and an anomalous cyclonic circulation appears to the east of Tibetan Plateau centered around $25^{\circ} \mathrm{N}$. The anomalous southwesterly between these two systems covers the eastern part of the Indochina, South China, and southeastern coastal China. The anomalous southwesterly weakens significantly when it reaches the Yangtze River region.

The strengthened southwesterly provides both the convergence-induced upward motion and moisture source for South China. Figure 10(c) displays the composite of the difference of the low-level (from surface to $700 \mathrm{hPa}$ ) convergence between the abundant spring precipitation years and scarce spring precipitation years in South China. It is evident that large scale convergence occurs in South China region and western Pacific subtropical high region, with its maximum value reaching $-40 \times 10^{-3} \mathrm{~s}^{-1}$. This large anomalous convergence leads to strong vertical motions in the South China region, as shown in Figure 10(d). The strong vertical motion (with its value exceeding the absolute value of $-20 \times 10^{-3} \mathrm{~Pa} \mathrm{~s}^{-1}$ ) appears from $20^{\circ}-30^{\circ} \mathrm{N}$ and extends from surface to $200 \mathrm{hPa}$ level, with strongest vertical motion reaching a value of $-36 \times 10^{-3} \mathrm{~Pa} \mathrm{~s}^{-1}$. The strong anomalous vertical motion and abundant low-level moisture 

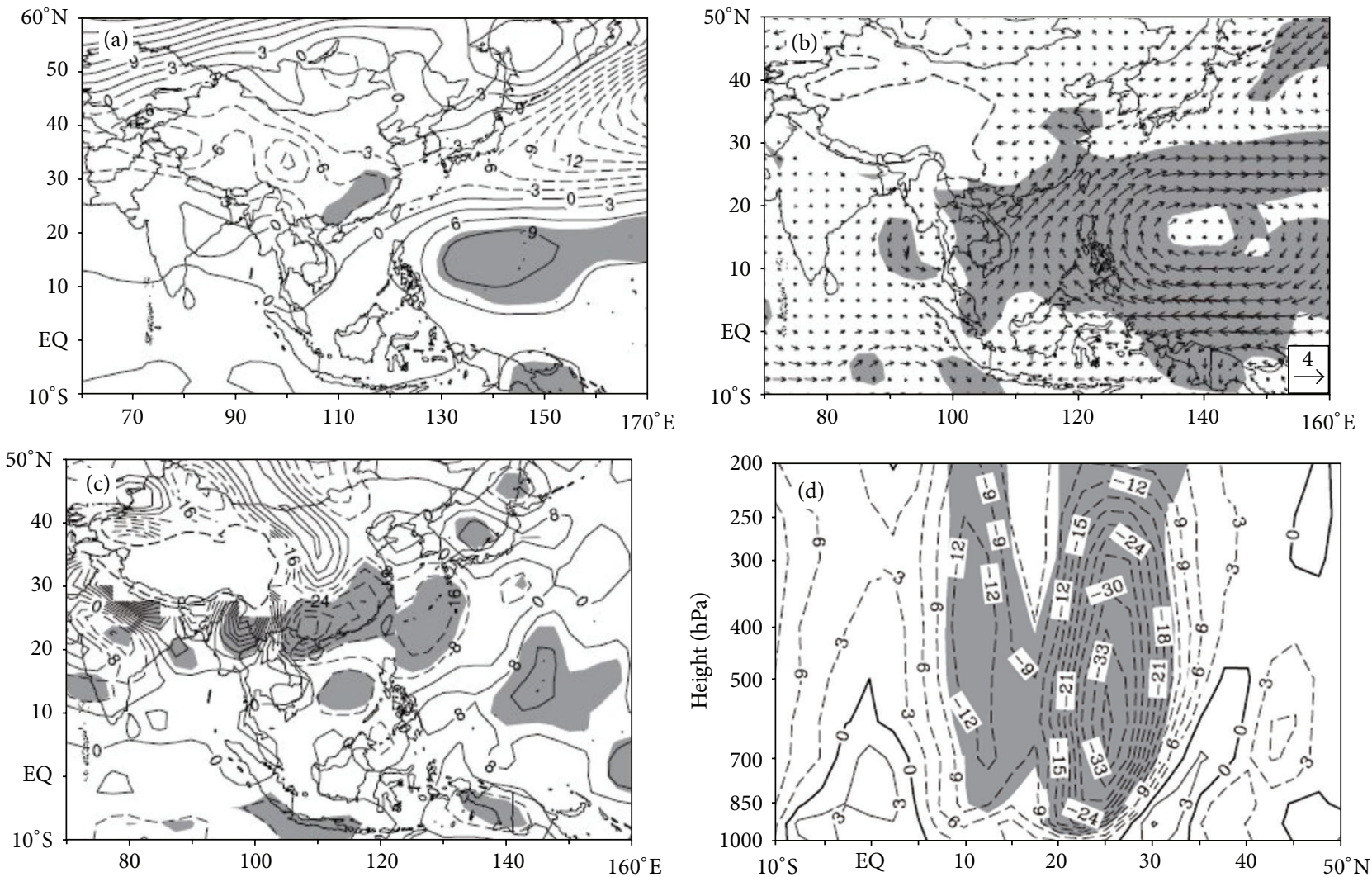

Figure 10: The differences of physical fields between the abundant spring precipitation years and scarce precipitation years in the South China: (a) the $500 \mathrm{hPa}$ geopotential height (dagpm); (b) the $850 \mathrm{hPa}$ wind $\left(\mathrm{ms}^{-1}\right)$; (c) the low-level convergence $\left(10^{-3} \mathrm{~s}^{-1}\right)$; and (d) the zonally averaged (along $110^{\circ}-120^{\circ} \mathrm{E}$ ) vertical velocity in $\mathrm{p}$-coordinate $\left(10^{-3} \mathrm{~Pa} \mathrm{~s}^{-1}\right)$.
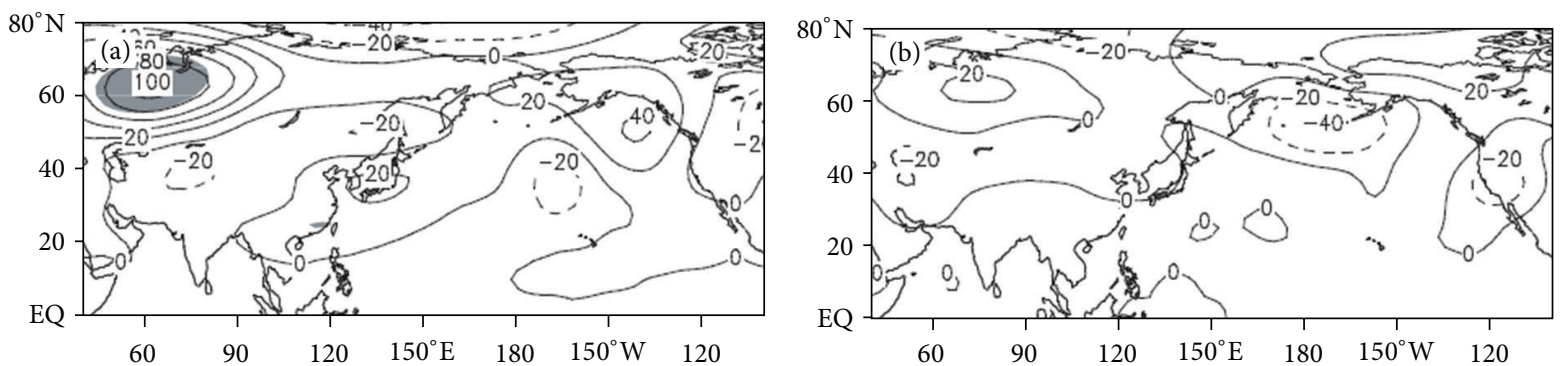

FIGURE 11: Composite $500 \mathrm{hPa}$ level geopotential height for flooding spring years (a) draught spring years (b) in in South China (unit: gpm).

convergence generates the abnormal precipitation in the abundant South China spring precipitation years.

It could be found from Figure 11 that there are abnormal regions passed the significant test located in the western tropical Pacific, northwestern North America, and mid latitude in northwest Atlantic in the $500 \mathrm{hPa}$ height field. Similar to the Pacific-North American teleconnection pattern, it is positive difference in the western tropical Pacific and from northwestern North America to North Pole; negative difference at mid latitude in Asia and mid latitude in North America. It results in higher geopotential height over the western tropical Pacific and stronger Aleutian Low in March in years when spring precipitation in South China is abundant.
Coincident with the tropical-subtropical circulations, the Aleutian Low strengthens and the westerly in midlatitudes east Asia weakens in the early spring of the abundant spring precipitation years in South China. Such type of mid and high latitude circulation pattern provides a favorable environment for the mid and high level cold air mass to move southward, leading to the dropping of the temperature of the tropical western Pacific and further strengthening the western Pacific subtropical high. The southeastward retreating of the western Pacific subtropical high leads to the large moisture transport from ocean reaching only to the latitudes of the South China. The meeting of the cold air from midlatitude and warm moist air from tropics leads to the abnormal precipitation in the 
South China region [21]. In the years of scarce spring precipitation in the South China, there is an anomalous anticyclonic circulation over the vicinity of the South China [22]. Such an anticyclonic circulation maintains the anomalous downward motion. At the same time, positive large scale geopotential height anomaly appears in the vicinity of Ural mountains, so as in the eastern China, Japan, and its eastern neighboring regions, coincident with the weakening of the grand eastern Asian trough. Such a circulation pattern prevents the cold air in mid and high latitude to move southward, thereby forming an environment not favoring the occurrence of spring precipitation in the South China.

\section{Conclusions and Discussions}

Consider

(1) The precipitation in South China is spatiotemporally uneven, with the scarcest spring precipitation $(212.1 \mathrm{~mm})$ at Weizhou Island $\left(109^{\circ} 06^{\prime} \mathrm{E}, 21^{\circ} 02^{\prime} \mathrm{N}\right)$ of Guangxi Zhuang Autonomous Region and most abundant spring precipitation $(808.3 \mathrm{~mm}$ ) at Fuogang $\left(113^{\circ} 31^{\prime} \mathrm{E}, 23^{\circ} 53^{\prime} \mathrm{N}\right)$ of Guangdong Province. In general, the eastern and southeastern regions of South China are rainfall abundant area; and the remaining parts of South China are rainfall scarce area. The first eigenvector resulting from EOF analysis is uniform over the whole South China; the second eigenvector features two natural climatological regimes; and the third eigenvector has six distinctive natural climatological regimes: (1) the northern part of South China which features hilly areas of both Guangdong and Guangxi; (2) the northwestern region of Guangxi; (3) the southwestern region of Guangxi; (4) the central South China (including the central parts of both Guangdong and Guangxi); (5) the southern South China region (including the central regions of both Guangdong and Guangxi); and (6) Leizhou Peninsula region.

(2) The spring precipitation in the South China contains significant multiscale variability. The largest interannual fluctuation occurred in 1973 and had a value of $716.5 \mathrm{~mm}$ while the smallest interannual fluctuation occurred in 1963 with a value of $189.9 \mathrm{~mm}$. The maximum interannual fluctuation is almost four times as large as that of the minimum. The South China spring precipitation experienced variability of a below-above-below-above-below-above-below pattern. Spectral analysis of the spatial mean spring precipitation in South China shows periodicity of 4 years, 8 years, and 14 years.

(3) The spring precipitation in the South China contains significant interdecadal variability. The 1980 s is the decade of most abundant spring precipitation while the 1960s is the decade of the fewest spring precipitation. An abrupt increment occurred in 1964 while an abrupt decrement occurred in 2002. These two abrupt changes are statistically significant at a significance level of $a=0.05\left(u_{0.05}= \pm 1.96\right)$.
(4) The atmospheric circulation patterns associated with the abundant spring precipitation and scarce spring precipitation in South China are significantly different. In the abundant years, on the one hand, the Aleutian Low strengthens and the westerly in midlatitudes east Asia weakens in the early spring, favoring the mid and high level cold air mass moving southward. On the other hand, the western Pacific subtropical high retreats southeastward, leading to the large moisture transport from ocean reaching only the latitudes of South China. The meeting of the cold air from midlatitude and warm moist air from tropics leads to the abnormal precipitation in the South China region. In the years of scarce spring precipitation in the South China, there is an anomalous anticyclonic circulation over the vicinity of the South China. Such an anticyclonic circulation maintains the anomalous downward motion. In the meantime, positive large scale geopotential height anomaly appears in the vicinity of Ural mountains, as well as in the eastern China, Japan, and its eastern neighboring regions, causing the weakening of the southern branch of the grand eastern Asian trough and the northwestward shift of the western Pacific subtropical high. Such a circulation pattern prevents the cold air in mid and high latitude to move southward, thereby not favoring the occurrence of spring precipitation in the South China.

\section{Conflict of Interests}

The authors declare that there is no conflict of interests regarding the publication of this paper.

\section{Acknowledgments}

This work has been funded by the National Basic Research Program of China (Grant no. 2013CB430200 (2013CB430206)) and the Sixth Program Ten Talented People of the Gansu Province Meteorological Bureau, China (Grant no. 06).

\section{References}

[1] H. L. Liu, Q. Zhang, W. C. Hu, and J. Q. Guo, “The changing characteristics of spring precipitation in Northwest China and their spatial differentiation during 1961-2011," Journal of Glaciology And Geocryology, vol. 35, no. 4, pp. 857-864, 2013 (Chinese).

[2] H. L. Liu, Q. Zhang, J. Q. Guo, S. Wang, Y. Cui, and X. Y. Wen, "Anomaly space distribution and decadal variability of spring precipitation in Gansu Province," Journal of Glaciology and Geocryology, vol. 36, no. 5, pp. 1143-1150, 2014 (Chinese).

[3] S. J. Lu, Climate of South China, Meteorological Press, Beijing, China, 1990, (Chinese).

[4] H. L . Liu, Q. Zhang, S. Wang, J. Q. Guo, and H. Yang, "Abnormal spatial distribution of spring precipitation and its decadal variability in the Hexi corridor in the arid area of 
Northwest China," Journal of Desert Research, vol. 34, no. 5, pp. 1386-1392, 2014 (Chinese).

[5] H. L. Liu, Q. Zhang, J. Q. Guo, S. Wang, and H. W. Zhang, "Spatial differentiation of spring precipitation in the Heihe River basin and its correlation with the river flow," Journal of Desert Research, vol. 34, no. 6, pp. 1633-1640, 2014 (Chinese).

[6] H. X. Duan, S. P. Wang, and J. Y. Feng, "The drought situation and its influence and cause in 2010 spring," Journal of Arid Meteorology, vol. 28, no. 2, pp. 238-244, 2010 (Chinese).

[7] Z. X. Hao, J. Y. Zheng, Q. S. Ge, and X. Z. Zhang, "Spatial patterns of precipitation anomalies for 30 -yr warm periods in China during the past 2000 years," Acta Meteorologica Sinica, vol. 26, no. 3, pp. 278-288, 2012.

[8] X. X. Bai, C. Y. Li, and L. Li, "Numerical simulation study of the Madden-Julian Oscillation in influences on spring precipitation in China," Acta Meteorologica Sinica, vol. 70, no. 5, pp. 986-1003, 2012 (Chinese).

[9] R. J. Wan and G. X. Wu, "Temporal and spatial distributions of the spring persistent rains over Southeastern China," Acta Meteorologica Sinica, vol. 23, no. 5, pp. 598-608, 2009.

[10] Z. P. Wen, N. G. Wu, Y. R. Feng, L. X. Lin, Z. J. Yuan, and B. H. Chen, "A quantitative diagnosis for the mechanisms of spring droughts in South China," Chinese Journal of Atmospheric Sciences, vol. 31, no. 6, pp. 1223-1236, 2007 (Chinese).

[11] D. J. Gu, Z. P. Ji, A. L. Lin, and L. S. Hao, "The variation and precursor of Guangzhou spring rainfall," Journal of Tropical Meteorology, vol. 21, no. 6, pp. 579-587, 2005 (Chinese).

[12] M. S. Zhou, M. Q. Jian, and Y. T. Qiao, "April-May persistent drought events in South China and the related general circulation background," Acta Meteorologica Sinica, vol. 71, no. 1, pp. 76-85, 2013 (Chinese).

[13] H. Y. Li, Z. H. Lin, Y. Song, and H. Chen, "Zonal seesawlike distribution of spring precipitation over South China and characteristics of atmospheric circulation in anomalous climate years," Meteorological Monthly, vol. 39, no. 12, pp. 1616-1625, 2013 (Chinese).

[14] X. Z. Li, W. Liang, and Z. P. Wen, "Characterstics of the atmospheric water vapor and its relationship with rainfall in South China in northern autumn, winter and spring," Journal of Tropical Meteorology, vol. 26, no. 5, pp. 626-632, 2010 (Chinese).

[15] R. J. Wan, T. M. Wang, and G. X. Wu, “Temporal variations of the spring persistent rains and SCS subtropical high and their correlations to the circulation and precipitation of the East Asia summer monsoon," Acta Meteorologica Sinica, vol. 66, no. 5, pp. 800-807, 2008 (Chinese).

[16] J. P. Han, H. J. Wang, and D. B. Jiang, "Interannual variation of spring precipitation and circulation in South China as simulated by a coupled model," Climatic and Environmental Research, vol. 11, no. 2, pp. 194-202, 2006 (Chinese).

[17] F. Y. Wei, The Modern Technology of Climate Statistics and Diagnose, Meteorological Press, Beijing, China, 2nd edition, 2007, (Chinese).

[18] H. L. Liu, Q. Zhang, J. G. Zhang, W. C. Hu, J. Q. Guo, and S. Wang, "Changing characteristics and spatial differentiation of spring precipitation in Southwest China during 1961-2012," Chinese Physics B, vol. 24, no. 2, Article ID 029201, 2015.

[19] D. S. Yang and Y. B. Liu, Dynamic Meteorology, Meteorological Press, Beijing, China, 1983, (Chinese).

[20] P. P. Jiang and P. Zhao, “The interannual variability of spring rainy belt over southern China and the associated atmospheric circulation anomalies," Acta Meteorologica Sinica, vol. 70, no. 4, pp. 681-689, 2012 (Chinese).
[21] L. P. Deng and Q. Q. Wang, "On the relationship between precipitation anomalies in the first raining season (April-June) in southern China and SST over offshore waters in China," Journal of Tropical Meteorology, vol. 18, no. 1, pp. 45-55, 2010 (Chinese).

[22] H. Y. Li, Z. H. Lin, Y. Song, H. Chen, and J. Y. Xu, "Analysis of the possible factors that influence March precipitation anomalies over south China," Chinese Journal of Atmospheric Sciences, vol. 37, no. 3, pp. 719-730, 2013 (Chinese). 

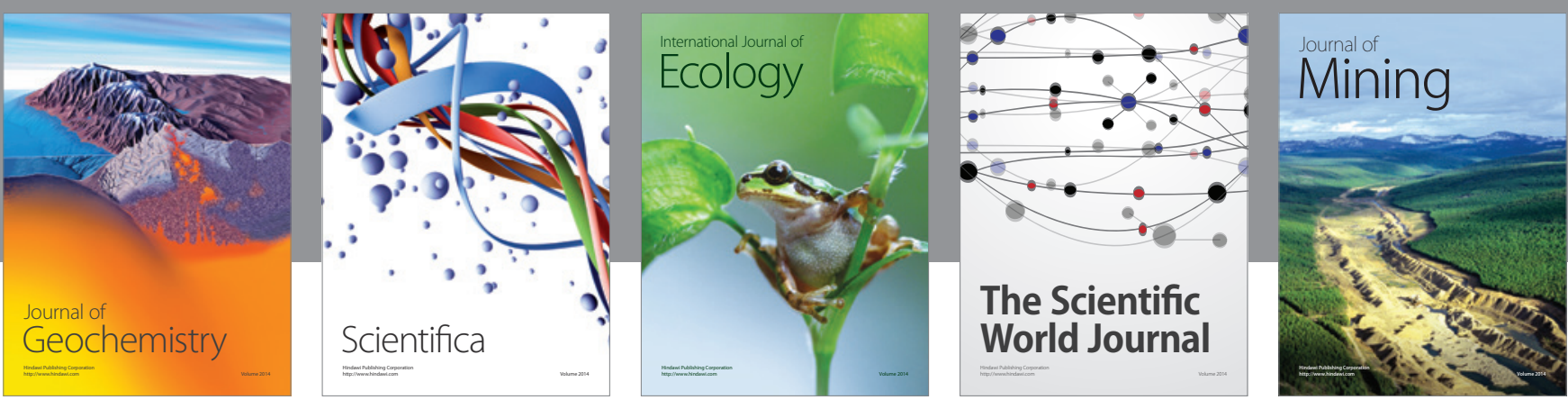

The Scientific World Journal
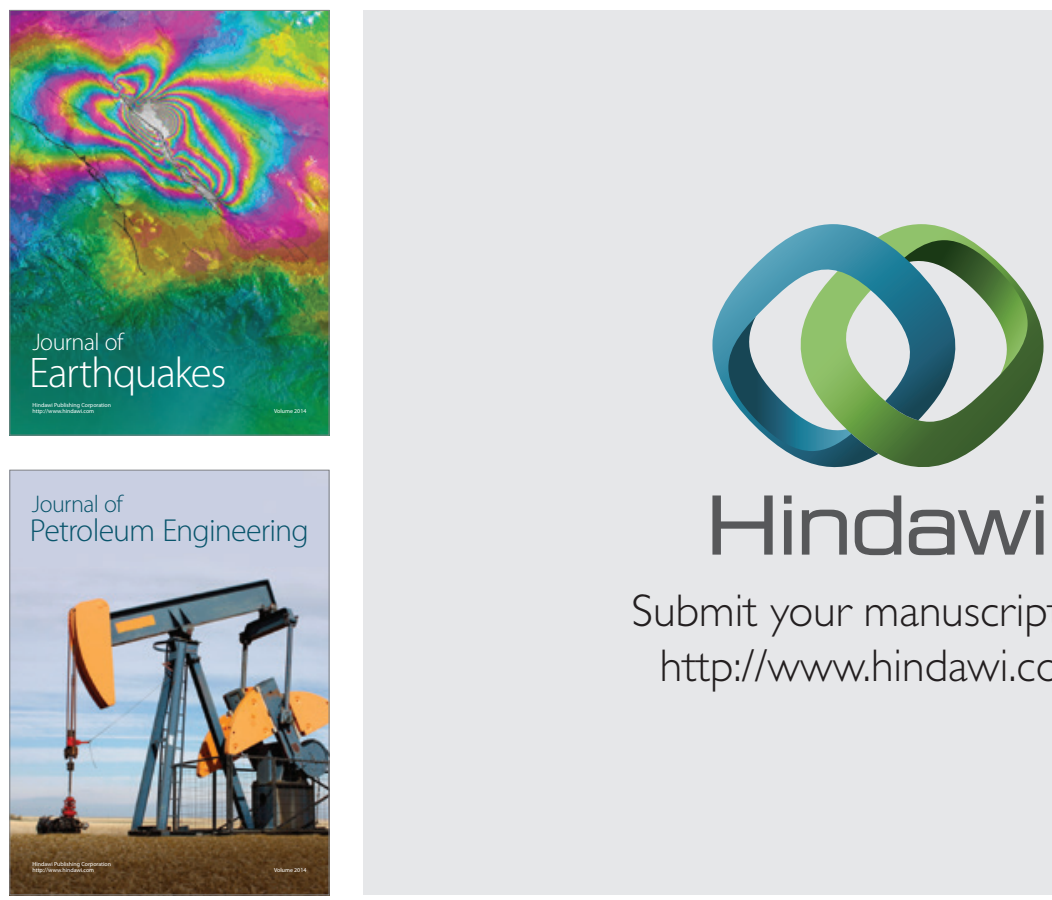

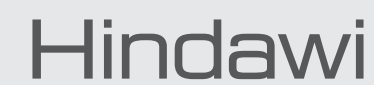

Submit your manuscripts at

http://www.hindawi.com
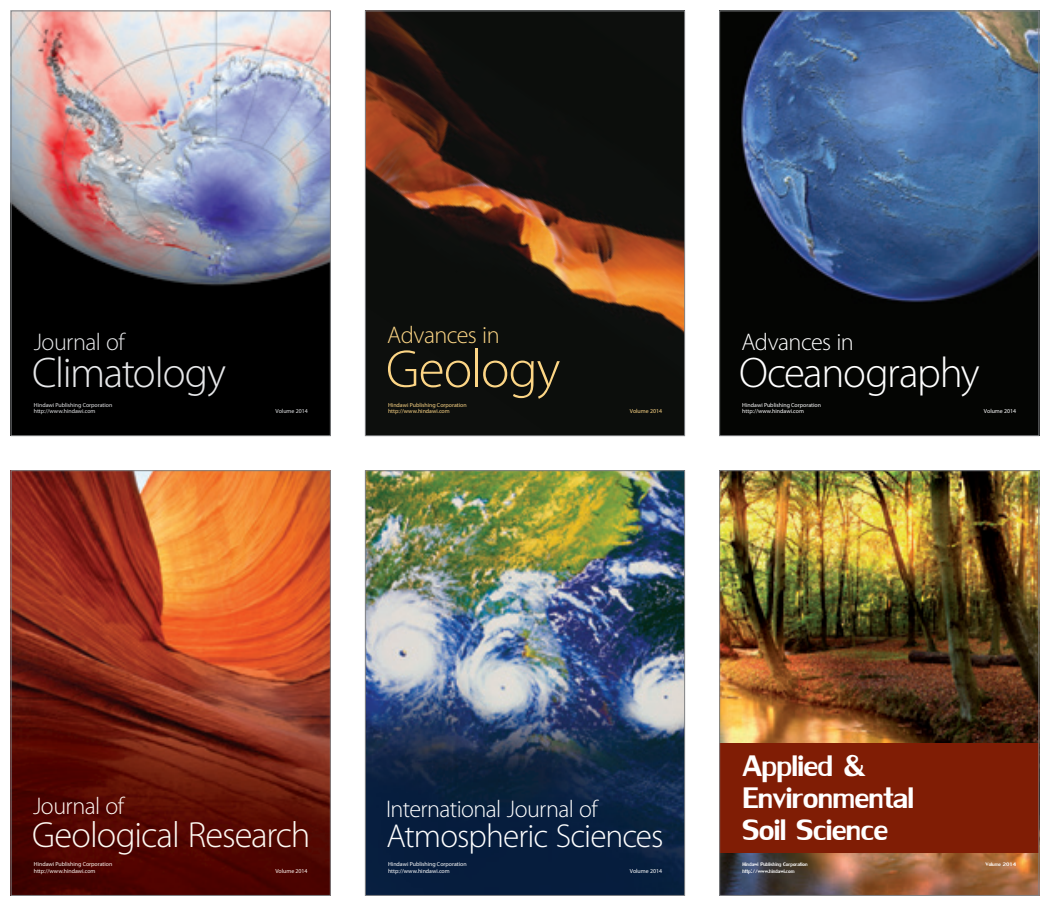
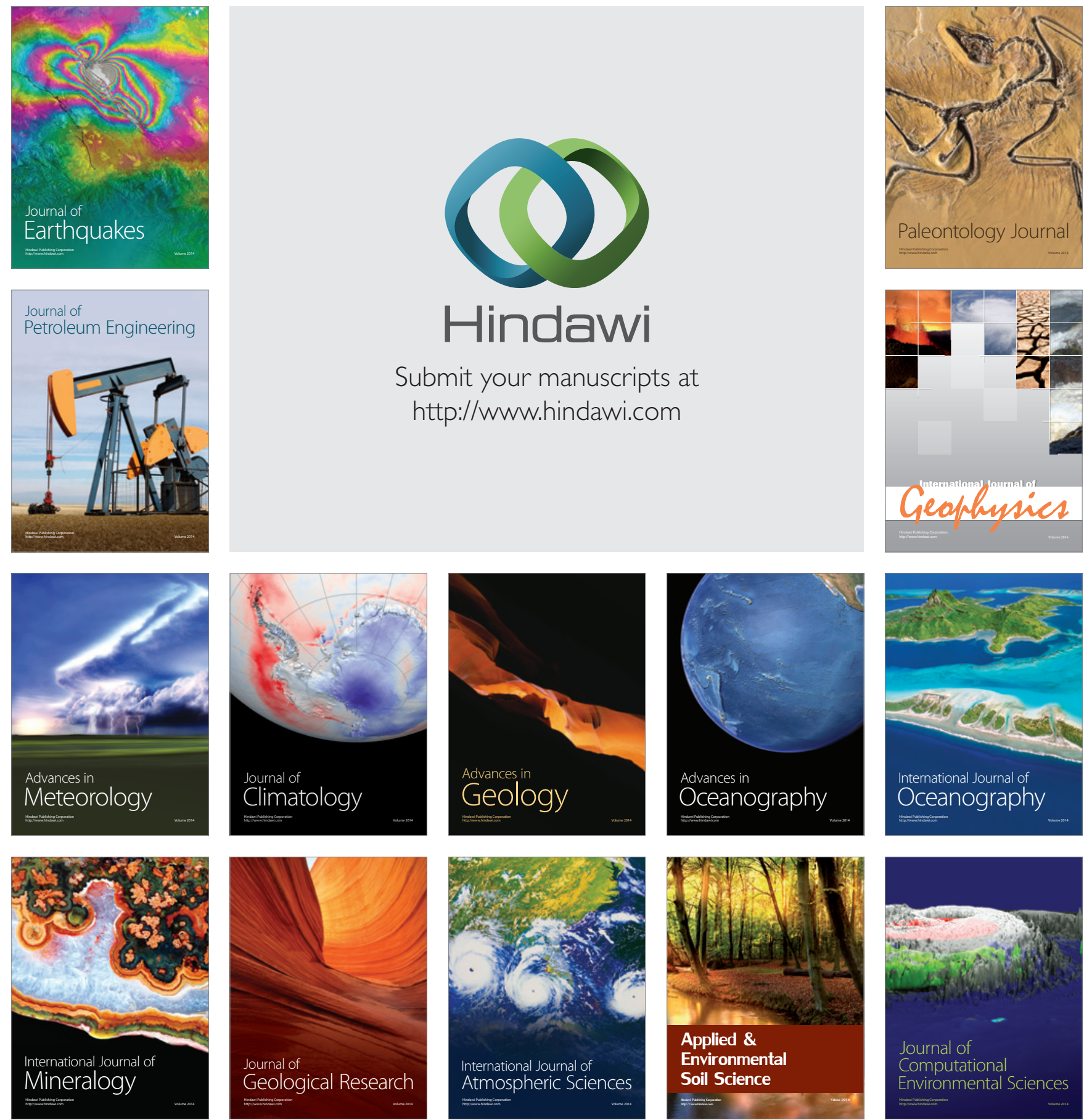